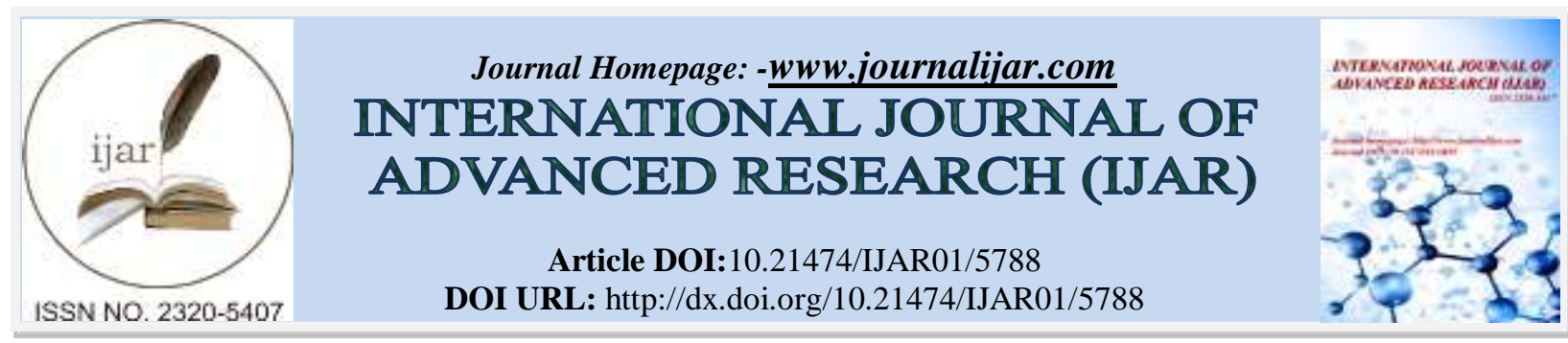

REVIEW ARTICLE

\title{
ANALYSIS OF SOLAR STEAM GASIFICATION OF CARBON- RICH FLY ASH TO PRODUCE SYNTHETIC GAS.
}

Dr. Surabhi.
Department of Applied Chemistry, Pillai college of Engineering, New Mumbai, India.

\section{Manuscript Info}

Manuscript History

Received: 06 September 2017

Final Accepted: 08 October 2017

Published: November 2017

\begin{abstract}
Converting waste material generated from various sources into syn gas and using it for power generation has emerged as means of converting abundantly available wastes into clean and efficient electrical energy.

Solar thermal systems use focusing mirrors to concentrate the sun's rays and efficiently achieve ultra-high temperatures. The produced syngas can burned in the oxidiser at temperature up to $700^{\circ} \mathrm{F}$ with flue gases to produce high-pressure steam that drives the turbine for producing electricity. The process produces a flexible product, synthesis gas, which can be chemically converted to a number of useful fuels (e.g. gasoline, diesel, hydrogen).This process is much faster (seconds vs. days), simpler, and has the potential to produce a wider range of chemical products. By 2030, world energy demand will climb from a current level of $18 \mathrm{TW}$ to $28 \mathrm{TW}$. At the same time, concerns over the environmental and national security impacts of fossil fuel use are driving the search for a fuel source that is abundant, clean, and producible in India. Fuels produced from waste (e.g. switch grass, agricultural residues, forestry waste) could provide a large piece of this energy puzzle. This innovation proposes to use solar thermal energy to overcome the problems encountered in conventional conversion. Such an approach lies on the interface between two renewable energy technologies (solar and wastes) and is uniquely positioned to maximize the positive qualities of both.
\end{abstract}

Copy Right, IJAR, 2017,. All rights reserved.

\section{Introduction:-}

The heat required for operating a conventional thermochemical gasifier is provided by combustion, either of a fossil fuel (e.g. natural gas) or of the feedstock itself. Obviously, processing with natural gas is neither renewable nor carbon-neutral, and the price will be strongly linked to the price and availability of natural gas.To maintain gasification temperatures between $500{ }^{\circ} \mathrm{C}$ and $800{ }^{\circ} \mathrm{C}$, up to $30 \%$ of the resource material must be combusted. Reaching temperatures where conversion efficiency and selectivity are extremely high $\left(1200{ }^{\circ} \mathrm{C}\right)$ require $35 \%-45 \%$ resource combustion, based on adiabatic flame temperature.

If natural gas is used, and equivalent amount of energy must be consumed to drive the gasification - it would make more sense to reform that fuel to syngas directly. High temperatures, at which conversion and selectivity have been shown to be improved, are expensive to attain, as too much of the feedstock must be used as fuel to maintain 
reaction temperatures. Solar thermal energy provides a means to efficiently and sustainably provide high temperature $\left(>1000{ }^{\circ} \mathrm{C}\right)$ process heat while utilizing an abundant but underused renewable resource.

\section{National Status:-}

Conventional industrial processes depend on hydrocarbon resources for producing fuels like Hydrogen/syngas and commodities like metals, lime etc. These industrial processes are highly energy and carbon intensive. The issues of fossil fuel depletion and climate change have resulted in development of solar industrial process solutions. Concentrated solar technology offers the option of converting solar energy into thermal, electrical and chemical forms. While conventionally concentrated solar energy is used for process heat and power generation applications, using it to drive chemical reactions is remarkable.

Processes that make use of solar heat to drive high temperature endothermic chemical reactions are known as solar thermo chemical processes. Solid carbon feed can be steam gasified in the temperature range of 1123 - $1883 \mathrm{~K}$ to produce syngas. Concentrated solar energy can efficiently achieve temperatures where conversion and selectivity of gasification are high $\left(1000^{\circ} \mathrm{C}-1200{ }^{\circ} \mathrm{C}\right)$. Use of solar energy removes the need for a combustion fuel and upgrades the heating value of the waste products. The syngas product of the gasification can be transformed into a variety of fuels usable with today's infrastructure.

The conversion of natural gas to hydrocarbons (Gas-To-Liquids route) is currently one of the most promising topics in the energy industry due to economic utilization of remote natural gas to environmentally clean fuels, specially chemicals and waxes.

\section{International Status:-}

The actual process consists of many reactions like steam gasification, hydrogasification, methane reforming and water gas shift reaction (1). Pressure - temperature conditions dictate the extent of each reaction that in turn decides the composition of product gas. The energy efficiency of solar coal gasification process is estimated at $46-50 \%$ (2).

Piatkowski et al. (3) gave a detailed review on thermodynamics, kinetics and reactor technology for gasification of coal based feedstock. Similar to methane reforming and decomposition processes, the reactors used for coal gasification can be classified as directly and indirectly heated reactors. Directly heated reactors developed so far are vortex flow and fluidized bed reactors, while packed bed and entrained flow reactors have been popular for indirect heating.

Pilot scale demonstration on solar gasification of solid carbonaceous feedstock has been done in EU programs SYNPET and SOLSYN. The project SYNPET was based on solar gasification of coal to produce syngas. In this project, a $5 \mathrm{~kW}$ vortex flow reactor was developed tested for steam gasification of pet coke (4), pet coke water slurry (5)and petroleum vacuum residue (6).

The vortex flow technology was then up scaled to demonstrate steam gasification of coal slurry in a pilot $500 \mathrm{~kW}$ plant (7). The project SOLSYN aimed at solar upgrading of solid carbon feed to produce high quality syngas that will be used to substitute fossil fuels in cement kiln.

Packed bed reactors can easily handle heterogeneous feedstock with varying composition, particle size and reactivity. The issues with packed bed reactors are lower heat/mass transfer in the porous bed that limits the reaction rate and energy conversion efficiency. It also increases ash build-up and leads to slagging and sintering inside the reactor $(8)$.

The research group in Japan is working on coal gasification in a fluidized bed reactor (9-11).

However it was found that for this reactor, the reaction zone was quite narrow and large temperature gradient existed between the light irradiated bed surface and inside bed. This heat transfer limitation of the bed was responsible for low performance of the solar fluidized bed reactor. To overcome this problem, the group has proposed the concept of an internally circulating fluidized bed reactor (12-14). 
Gasification is considered as one of the best method for the conversion of biomass because of space consideration, flexibility of fuel used, reducing the volume of solid waste \& recovery of energy (15).

To enable India to handle with the conventional and demanding state of a shortage of petroleum fuels for surface transport in the future, potential alternatives are examined and evaluated that can ensure adequate energy for the transport sector with acceptable environment implications. The possibility of large-scale hydrogen production from renewable resources holds promise for scalable achievement and sustainability in the future but this would require huge technological challenges to be overcome. (16)

This study describes the potential of this proposed fuel resource scenario for transport fuels and discusses the technological challenges that would have to be addressed for its large-scale implementation.

\section{Summary and Conclusion:-}

A solar thermal system consists of concentrating optical surfaces that focus the energy to a target. At this focal point, the original incident energy is concentrated to thousands of times its original intensity, allowing for very high temperatures to be achieved (>1000 ${ }^{\circ} \mathrm{C}$ ). By implementation of a cavity receiver, these high temperatures can be maintained very efficiently(17-18). Central receiver solar thermal systems are currently operating to produce electricity commercially in Spain, but the technology remains underdeveloped for application to chemical process systems(18). These researchers found that solar energy could be stored in the products with an efficiency (energy chemically stored divided by energy delivered) nearing 50\%, but did not operate above $1200 \mathrm{~K}$; at these temperatures, some higher hydrocarbons were formed(19).

One of the problem regarding production of syngas that they may contain some trace elements of impurities, which are removed through further processing and either recovered or redirected to the gasifier. Syngas is a primary source of sulfuric acid. If syngas contains a considerable quantity of nitrogen, the nitrogen must be separated to avoid production of nitric oxides, which are pollutants and contribute to acid rain production. Both carbon monoxide and nitrogen have similar boiling points so recovering pure carbon monoxide requires cryogenic processing, which is very difficult.

\section{References:-}

1. Müller R, Zedtwitz P v., Wokaun A, Steinfeld A. Kinetic investigation on steam gasification of charcoal under direct high-flux irradiation. Chem Eng Sci 2003; 58:5111-9.

2. Zedtwitz $\mathrm{P}$ v., Steinfeld A. The solar thermal gasification of coal - energy conversion efficiency and $\mathrm{CO}_{2}$ mitigation potential. Energy 2003; 28:441-56.

3. Piatkowski N, Steinfeld A. Reaction kinetics of the combined pyrolysis and steam-gasification of carbonaceous waste materials. Fuel 2010; 89:1133-40.

4. Zgraggen A, Haueter P, Trommer D, Romero M, Dejesus J, Steinfeld A. Hydrogen production by steamgasification of petroleum coke using concentrated solar power-II Reactor design, testing, and modeling. Int J Hydrogen Energy 2006; 31:797-811.

5. Zgraggen A, Haueter P, Maag G, Vidal A, Romero M, Steinfeld A. Hydrogen production by steam-gasification of petroleum coke using concentrated solar power-III. Reactor experimentation with slurry feeding. Int J Hydrogen Energy 2007; 32:992-6.

6. Zgraggen A. Hydrogen production by steam-gasification of carbonaceous materials using concentrated solar energy-IV. Reactor experimentation with vacuum residue. Int J Hydrogen Energy 2008; 33:679-84.

7. Vidal A, Denk T, Steinfeld L, Zacarías L, Almería T. Upscaling of a $500 \mathrm{~kW}$ Solar Gasification Plant. Proc. WHEC 2010, vol. 78, Forschungszentrum J lich GmbH, Zentralbibliothek, Verlag,: 2010, p. 177-81.

8. Piatkowski N, Wieckert C, Steinfeld A. Experimental investigation of a packed-bed solar reactor for the steamgasification of carbonaceous feedstocks. Fuel Process Technology 2009;90:360-6.

9. Kodama T, Kondoh Y, Tamagawa T, Funatoh A, Shimizu K, Kitayama Y. Fluidized Bed Coal Gasification with CO2 under Direct Irradiation with Concentrated Visible Light. Energy \& Fuels 2002:1264-70.

10. Kodama T, Gokon N, Enomoto S, Itoh S, Hatamachi T. Coal Coke Gasification in a Windowed Solar Chemical Reactor for Beam-Down Optics. J Sol Energy Eng 2014;132:1-6.

11. Etori T, Gokon N, Takeuchi a., Miki T, Yokota M, Kodama T. Flowability Control of Bed Materials in a Fluidized Bed Reactor for Solar Thermochemical Process. Energy Procedia 2015;69:1741-9.

12. Kodama T, Enomoto S, Hatamachi T, Gokon N. Application of an Internally Circulating Fluidized Bed for 
Windowed Solar Chemical Reactor with Direct Irradiation of Reacting Particles. J Sol Energy Eng 2008;130:14.

13. Gokon N, Ono R, Hatamachi T, Liuyun L, Kim H. $\mathrm{CO}_{2}$ gasification of coal cokes using internally circulating fluidized bed reactor by concentrated Xe-light irradiation for solar gasification. Int J Hydrogen Energy 2012;37:12128-37.

14. Abe T, Gokon N, Izawa T, Kodama T. Internally-circulating fluidized bed reactor using thermal storage material for solar coal coke gasification. Energy Procedia 2015; 69:1722-30.

15. Aly Moustafa Radwan, "An overview on gasification of biomass for production of hydrogen rich gas", Pelagia Research Library,Der Chemica Sinica, 2012, 3(2):323-335

16. Agarwal Avinash Kumar, Dhar Atul, "Biofuels and the Hybrid Fuel Sector" Proc Indian Natn Sci Acad 81 No. 4 September 2015 pp. $775-785$

17. Steinfeld, A., et al., "Solar Thermal Production of Zinc and Syn Gas via combined Zn Reduction and Ch4Reforming Processes", International Journal of Hydrogen Energy, 1995. 20(10) p. 793-804.

18. Steinfeld, A., et al., "Solar Processed metals as clean energy carriers and thermal splitters"; International Journal of Hydrogen Energy, 1998. 23(9): p. 767-774.

19. Gregg, D.W., et al., Solar Gasification of Coal, Activated Carbon, Coke and Coal and Biomass Mixtures. Solar Energy, 1980. 25(4): p. 353-364. 